\title{
Microneedles: An advancement to transdermal drug delivery system approach
}

\author{
Surendra Agrawal ${ }^{1 *}$, Suchi N. Gandhi ${ }^{1}$, Pravina Gurjar ${ }^{2}$, Nagendran Saraswathy ${ }^{1}$ \\ ${ }^{1}$ Shobhaben Pratapbhai Patel School of Pharmacy and Technology Management, SVKM's NMIMS, Mumbai 400056, India. \\ ${ }^{2}$ Sharadchandra Pawar College of Pharmacy, Otur, Maharashtra, India.
}

\author{
ARTICLE INFO \\ Received on: 17/09/2019 \\ Accepted on: 13/12/2019 \\ Available online: 05/03/2020 \\ Key words: \\ Transdermal system, \\ microneedle, microneedle \\ patents, microneedle \\ applications, skin barrier \\ function, role of microneedle.
}

\begin{abstract}
Novel drug delivery system offers several advantages which could outweigh the benefits of other drug delivery systems. The transdermal drug delivery system being one of them offers supremacy by by-passing the first pass metabolism which eventually helps in eradication of gastrointestinal irritation. However, the major drawback of the transdermal drug delivery system is the hindrance created via the stratum corneum. This protective barrier of the skin does not allow required penetration of the drug via skin into the systemic circulation. Thus, in order to overcome this hurdle, a replacement to this type of novel drug delivery system, namely, "microneedle drug delivery system" helped to improve various pitfalls of transdermal drug delivery system, such as skin barrier function, restrictions toward using of specific drugs only, bioavailability, patient compliance, diffusion rate, and plasma concentration level. A microneedle drug delivery system, thus, is advancement to transdermal drug delivery system which includes delivery of drug via microneedle into systemic circulation, thus increasing patient compliance and avoiding problems rendered by transdermal drug delivery system.
\end{abstract}

\section{INTRODUCTION}

Transdermal drug delivery system includes the delivery of drug via superficial lipophilic layer of the skin stratum corneum which is $10-15 \mu \mathrm{m}$ thick. Stratum corneum obstructs the entry of antigens, bacteria; thus defining the skin barrier function which eventually suppresses the percutaneous penetration. Henceforth, the utmost challenge included a search for an alternative way which would surpass the repercussions provided by the skin barrier function of stratum corneum (Bhowmik et al., 2013). Various innovations, such as iontophoresis, electroporation, sonophoresis, magnetophoresis, and use of penetration enhancers have been proposed by different researchers which could help elevate the permeation and delivery of drug (Bhowmik et al., 2013). Out of all, the concept of using "microneedles"-micron-sized needles for the delivery and penetration of the drug is considered to be the

\section{"Corresponding Author}

Surendra Agrawal, Shobhaben Pratapbhai Patel School of Pharmacy and Technology Management, SVKM's NMIMS, Mumbai 400056, India. E-mail:sagrawal@gmail.com most efficient method. The proof to this has been the experiments performed and subsequent results obtained by researchers and scientists (Bhowmik et al., 2013). A microneedle does not limit itself by improving only drug penetration. It has several other significant positive aspects (Wang et al., 2017). The drug delivery is specially preferred for pediatric application (Duarah et al., 2019) Thus, this review article focuses on microneedle drug delivery-its existence by overcoming the short comes of transdermal drug delivery system, types of microneedles used, different approaches for delivery, fabrication of microneedles, mechanism, materials, evaluation, and specific applications of microneedle drug delivery system.

\section{Conventional mode of drug delivery}

The delivery of the drugs plays a vital part in medicine and paramedical field. Normally, drug delivery system can be referred to as various ways, methods, and approaches for delivering the particular drug at proper site of action in order to obtain the highest amount of desired therapeutic effect. Normally, conventional modes of delivery include oral route, usage of carrier injections, or using novel approaches like transdermal drug delivery 
system for delivery of drug. With growing need for painless and less infectious prone way of drug delivery, microneedles are prone to fit the void for satisfying the requirement (Kaushik et al., 2001; Kshirsagar, 2000).

\section{Transdermal drug delivery system}

Transdermal drug delivery system (TDDS) is described as a novel drug delivery approach in which discrete and appropriate quantity of drug is delivered through the topmost layer of the skin which releases drug at a controlled rate for prolonged period of time into the systemic circulation. It can be described as a type of novel drug delivery approach which follows zero order drug release pattern (Kshirsagar, 2000).

The types of transdermal drug delivery include -

\section{Membrane permeation controlled TDD system}

In this type of transdermal drug delivery system, drug reservoir is in between backing layer and polymeric membrane. As shown in Figure 1(a), the drug reservoir area consists of the drug which is dispersed in the polymeric matrix solution to form a suspension like paste which is then delivered at a controlled rate through the rate controlling membrane which is non-porous or micro porous (Patel et al., 2012). Drugs like estradiol are delivered through membrane penetration (Chetkowski et al., 1986).

\section{Matrix diffusion controlled transdermal drug delivery system}

As shown in Figure 1(b), occlusive base plate, drug reservoir, polymeric membrane is present. The drug reservoir consists of the drug which is surrounded/coated with the matrix. Here, matrix could be any water-loving (hydrophilic) molecules or even lipophilic molecules. The dispersed form of drug and matrix forms a medicated disc like structure from which required amount of drug gets released at a controlled rate into the systemic circulation. The drug is in solution form in matrix and is backed by adhesive layer (Banerjee et al., 2014). Drugs like nitroglycerine can be delivered using this pathway (Rayment et al., 1985).

\section{Reservoir gradient controlled transdermal drug delivery system}

This type helps in dealing the issues related with nonzero release profile of the drug (Kesarwani et al., 2013). In this the drug and polymer matrix combined together in a reservoir could be converted in the form of a reservoir gradient along the diffusional pathway across the layer which leads to delivering a drug at a controlled rate as described in Figure 1(c). Glyceryl trinitrate is the drug which forms a deponit system for controlled delivery (Patel et al., 2012; Wiedersberg et al., 2014).

\section{Microreservoir dissolution controlled transdermal drug delivery system}

This type of drug delivery system is depicted in Figure 1(d) which has the combination of matrix and reservoir dispersion type of drug delivery system which includes two basic steps-Forming the drug reservoir which is done by suspending the drug in water soluble or aqueous solutions and then mixing/ dispersing the suspension with lipophilic polymer by strong mechanical force which results in the formation of numerous microscopic reservoirs and finally the release of the drug at controlled rate (Patel et al., 2012).

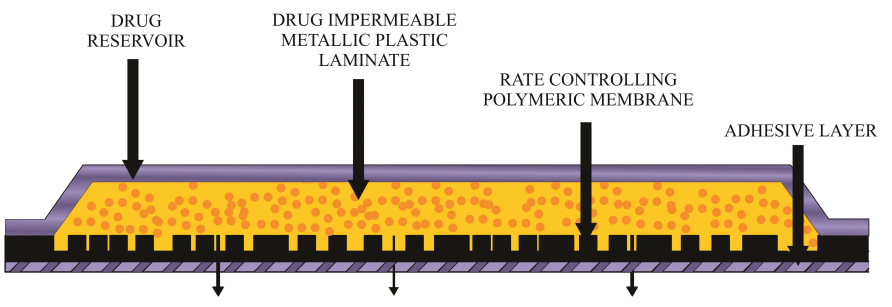

(a)

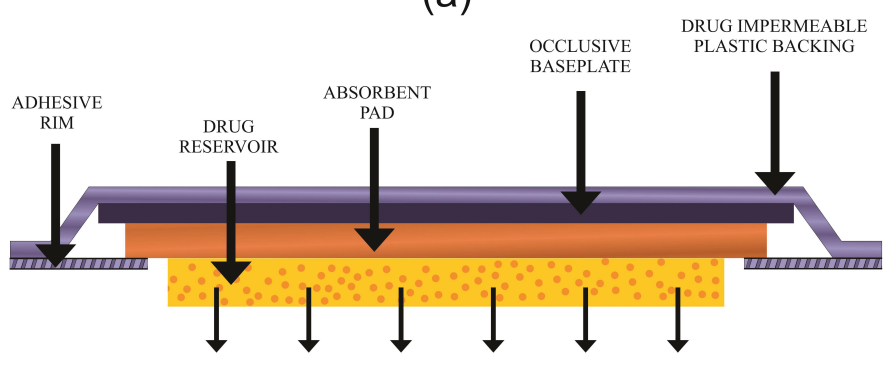

(b)

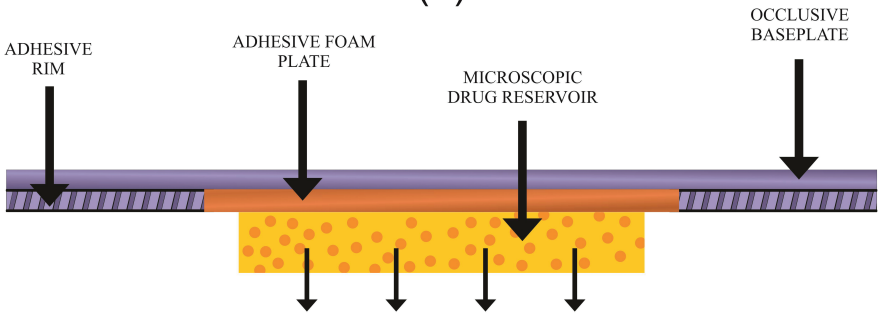

(c)

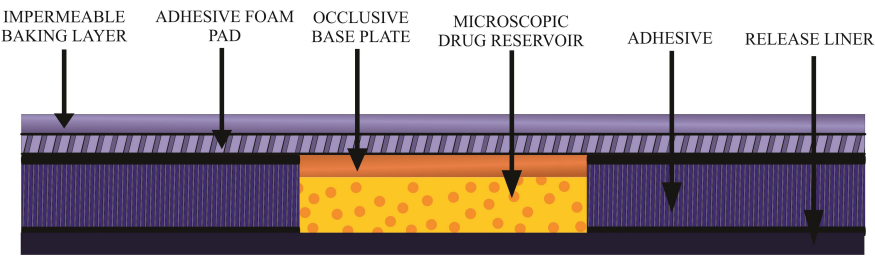

(d)

Figure 1. Types of transdermal drug delivery systems (a) Polymer membrane permeation TDDS (b) Polymer matrix diffusion TDDS (c) Drug reservoir gradient TDDS (d) Microreservoir dissolution TDDS explaining mechanism of different methods of drug delivery.

Transdermal patches are widely used. Several transdermal patches available are for Pain relief, Patches for reducing hypertension, Vitamin $B_{12}$ patches, Nicotine patches, etc. Trade name of certain transdermal products include CatapresTTS $^{\circledR}$, Climara ${ }^{\circledR}$, Climara pro $^{\circledR}$, Combipatch ${ }^{\circledR}$, Duragesic ${ }^{\circledR}$, Menostar $^{\circledR}$, Ortho Evra $^{\circledR}$, Oxytrol $^{\circledR}$, Transderm scop ${ }^{\circledR}$, Vivelle ${ }^{\circledR}$, Vivelle-Dot ${ }^{\circledR}$ (Wokovich et al., 2006). These transdermal products provide several benefits like it provides prolong effect with possibility of self-administration (Chaudhary et al., 2013), provides an alternative for patients who are unable to take oral medications, elimination of first past hepatic metabolism, avoid problems faced due to parenteral therapies, requires less dosage frequency (Allen and Ansel, 2013), visual confirmation while patch 
is applied, useful for trypanophobes (Raza et al., 2015), avoidance of enzymatic degradation, and gastrointestinal irritation. Also, it can be an alternative for the patients who are unable to take oral medications. Another advantage is that the drug release stops as soon as patch is removed. Despite of these ascendancies, there occur several stumbling blocks like unsuitableness for the drugs that irritate or sensitize skin and allowance for relative potent drugs only due to limitations related with skin permeability, problems related with non-adherence of a patch to skin, uneasiness while wearing a patch, change in barrier function of skin from site to site and person to person, the thickness of stratum corneum, poor solubility, allowance for only non-ionic, lipid and watersoluble molecules of particular molecular size, and shape limits the use of this type of drug delivery system. Hence, the more innovated type of drug delivery like microneedle drug delivery system can be employed to replace the setbacks offered by TDDS. Also, the transdermal drug delivery is unable to pass through stratum corneum which is the biggest limiting factor (Lampe et al., 1983; Ledger, 1992). The different transdermal systems currently available in the market, which could also be delivery with more effectiveness by microneedle drug delivery systems, are mentioned in Table 1.

\section{Microneedle drug delivery system}

The overarching response to microneedles is due to the concept of disrupting the stratum corneum layer of skin which can lead to smooth pathway for the entry of desired molecules. A microneedle drug delivery system can, thus, be explained as a Novel drug delivery system approach in which drug is delivered into the systemic circulation through the needles. The system in which micron-sized needles pierce the superficial layer of the skin and diffuses the drug across the epidermis layer which is then passed on into the blood capillary region for active absorption (Silpi et al., 2011) as microneedles are short and thin they help in avoiding the pain caused to patient (Shilpa et al., 2001). This could be achieved by Microfabrication technology (Bhushan and Caspers, 2017; Donnelly et al., 2010). With passing time, different materials, such as dextrin, stainless steel, ceramic, and maltose were utilized for preparing the microneedles (Donnelly et al., 2010). Few years later, pattern of permeability of drug to the skin via microneedles was studied which lead to a conclusion that permeability factor through microneedles could be elevated to three to four times as compared to that of TDDS. It was observed that the skin barrier function could be overcome by using micron-sized needles. Later, different materials through which microneedles could be fabricated were introduced. Hence, this lead to the inception of microneedles as a solution for more productive results in terms of bioavailability and permeation of drug. Scientists put down efforts using technology for proper optimization and geometrical measurements required for achieving accurate insertion in the skin of human which was major goal with respect to microneedle (Kong et al., 2011).

\section{TYPES OF MICRONEEDLES}

\section{Solid microneedle}

These microneedles use the passive diffusion path (Larraneta et al., 2016). Solid microneedles follow two steps, as shown in Figure 2, in which the microchannels in the skin are first created by inserting the microneedle, followed by allowing the drug formulation to pass over the generated microchannels (Kaur et al., 2014). Solid silicon microneedles proved to be the most prominent approach because of their sufficient biocompatibility (Wei et al., 2010). The manufacture of such a type of microneedle involves the use of various materials, such as polymers (Park et al., 2006), stainless steel metal (Martanto et al., 2004), biodegradable polymers (Park et al., 2005), and silicon (Li et al., 2010), for which silicon is the most important material to be used. Food and Drug Administration must approve these materials before fabrication starts on the basis of biocompatibility and safety (Kotzar et al., 2002). For proper production, various methods are used. One possibility is the use of thermal oxidation and lithography, wherein silicon on insulator wafer and oxide layer is processed to form a silicon oxide layer by thermal oxidation and lithography
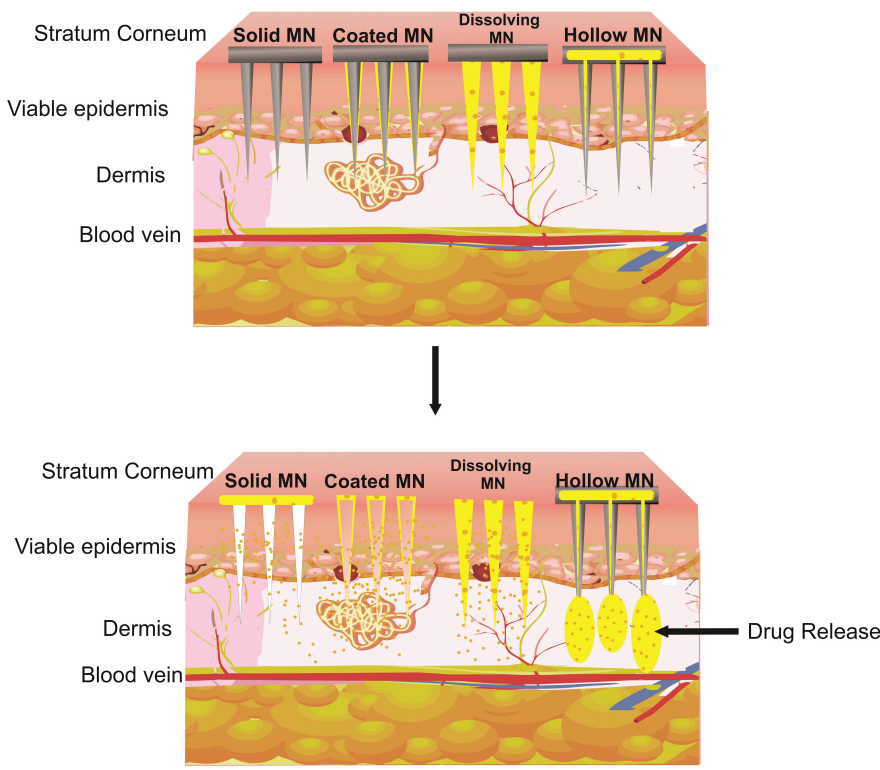

Figure 2. Mechanism of delivery of drugs by four types of Microneedles solid, coated, dissolving and hollow.

Table 1. Overview of the different transdermal drugs in market, specific disease treated, type of transdermal mechanism used, main advantages, and side effects.

\begin{tabular}{|c|c|c|c|c|c|}
\hline Drug Used & Type of disease treated & Type of TDD used & Advantages & Side effects & Reference \\
\hline Estradiol & Postmenstrual syndrome & Membrane & Reduce problems related with menopause & Breast tenderness & (Utian, 1987) \\
\hline Scopolamine & Motion sickness & Matrix & Reduces motion sickness & Oral administration & (Clissold and Heel, 1985) \\
\hline Testosterone & Hypogonadism & Reservoir & Increase muscle mass & Sleep apnea, skin reaction & (Wang et al., 2000) \\
\hline Rivastigmine & Dementia & Microreservoir & Alzheimer's Disease & Spinning sensation & (Kurz et al., 2009) \\
\hline Fentanyl & Pain relief & Reservoir & Decrease in oral mucositis pain & Convulsions, dry mouth & (Kim et al., 2005) \\
\hline
\end{tabular}


to obtain the first layer. The second layer (parylene coated) is deposited thereon to protect and isolate the chip. Furthermore, the microneedle electrode assembly is emancipated by separating the silicon oxide layer. Thus, the silicon array is obtained by modifying the parylene layer, which was previously under the silicon oxide layer, as a carrier layer of the solid silicon microneedle obtained by simply depositing the parylene layer to impart adhesives and strength to the microneedle (Wang et al., 2012). The main precision that emanates from a solid silicon microneedle is the rare occurrence of inflammatory or infectious conditions (VicentePerez et al., 2017). However, the high silicon cost is causing a setback in the use of silicon as the material for solid microneedles (Yue et al., 2009). Thus, a solid microneedle can also use other materials, such as parylene (Johnson and Wise, 2010), polyimide (Seo et al., 2004), nickel (Wang et al., 2007), titanium (Fofonoff et al., 2002), Polymethyl methacrylate, and polyvinyl (Matteucci et al., 2009).

\section{Drug-coated microneedles}

These type include coating of the drug on the solid microneedle before inserting it into the skin (Gill and Prausnitsz, 2007a). The coated microneedle is inserted into the skin where the drug gets dispersed into the systemic circulation. This system is utilized to deliver complex and macro molecules, including Deoxyribonucleic acid, drugs, like desmopressin, parathyroid hormone, and vaccines (Gill and Prausnitsz, 2007b, Quinn et al., 2014), peptides (Cormier et al., 2004), proteins (Matriano et al., 2002). Different methods like micro dip-coating for vaccine delivery (Koutsonanos et al., 2009) are used for fabricating microneedles onto which a drug solution can be coated to obtain a drug-coated microneedle ready for administration. Other method for developing coating microneedle include fabrication via laser cutting in which stainless steel material is used and according to the required acreage the sheet is cut by allowing infrared rays to pass through it. The obtained cutout is then cleaned by using proper cleanser. Furthermore, the electro polishing is required which is done by using copper plate which acts as a cathode and microneedles to be obtained would act as anode. The procedure requires continuous vibration in order to avoid the unwanted air bubbles. Microneedles are then cleansed using the de-ionized water followed by hot water which are then allowed to dry and the stored at optimum temperature. A coating solution is then prepared of the drug to be coated and microneedle is then coated using dip-coating technique. Coated microneedle is specifically used in treating enuresis, diabetes insipidus, hemophilia A, Willebrand's disease and certain trauma induced diseases (Gill and Prausnitz, 2007a).

\section{Dissolving microneedles}

These type of microneedles include usage of the biocompatible polymers like poly vinyl alcohol (Chu et al., 2010), carboxymethyl cellulose (Guo et al., 2013), or sugars (Miyano et al., 2005) which on insertion into the skin releases the drug and dissolves into the systemic circulation due to which a controlled release is obtained. The needle or the coating on the needle dissolves itself to release drug (Lee et al., 2008; 2011; Matriano et al., 2002). The main advantage is low cost of polymers and usage of water-soluble materials. But, one of the major downsides is deposition of polymers into the skin. These are prepared by lithographic approach (Moga et al., 2013) or a two-layered approach in which two plates are used. Drug and polymer are mixed and the solution formed is allowed to pass into the holes of the array. The push and pull movement is enforced onto the two plates placed parallel to each other. The polymeric solution is allowed to pass into plate below and the top plate is removed at the end after the dissolving microneedle have been fabricated as the polymeric solution gets solidified resulting in conical shaped microneedles which can be mostly used in administering influenza vaccine (Roxhed and Griss, 2008; Sullivan et al., 2008). Recently, Wu et al. (2016) prepared sinomenin loaded dissolving microneedles using a specialized fabrication technique using biocompatible polymers. (Wu et al., 2008).

\section{Hollow microneedles}

These microneedles are the one which allows the passage of the drug through the hollow bore channel present in the needle. The needle is inserted into the skin and the drug is allowed to pass through the bore which diffuses into the systemic circulation (Kurz et al., 2009). It is made up of various materials, such as silicon, metals (Chandrasekaran and Frazier, 2003; Roxhed and Griss, 2008; Roxhed et al., 2008), glass (Wang et al., 2006), and polymers (Sammoura et al., 2007). The main obstacle of hollow microneedle is the problem of clogging of the bore which leads to resistance to flow (Gardeniers et al., 2003). It can be manufactured by using lithographic technique which ultimately helps in intradermal drug delivery (Laurent et al., 2007). For fabrication, a silicon wafer is used onto which the photoresist layer is spinned and the deep molds are formed after the ultraviolet rays are allowed to pass through the molds. By wet etching process, the $\mathrm{KOH}$ solution is used due to which silicon wafer gets etched and the required microneedles are obtained by cutting silicon wafer into a microneedle array (Torin et al., 2011). Hollow microneedles are utilized in extraction of the blood sample by least amount of invasion. It helps to replace traditional technique of utilizing hypodermic needle (Li et al., 2013). The mechanism of various microneedles is described in Figure 2.

\section{Approaches}

Each and every microneedle whether it is solid or drug coated follow certain common steps in mechanism. Microneedles when inserted leads to mechanical disruption of the skin creating pore, and then, the drug coated on the needle is dispersed in the systemic circulation. Microneedles firstly disrupt the stratum corneum region of the skin. Stratum corneum includes skin barrier function (Bouwstra and Ponec, 2006) and microneedle helps to eradicate the problem of skin barrier function of stratum corneum. Hence, microneedles create a pathway for drug to directly get delivered into the blood rich region bypassing the stratum corneum which is not the case in transdermal drug delivery system. To give the desired outcome, it follows poke and patch, coat and poke, poke and release, poke and flow approach as discussed in Table 2. It depends on the fabrication of a microneedle which can be inplane or out-plane. In-plane microneedles are parallel to the surface and out-plane microneedles are perpendicular to the surface as shown in Figure 3 (Van der Maaden et al., 2012). 


\section{Clinical Trials on Microneedle Patch}

In order to understand the working and advantages of microneedle patches over the hypodermic needle or any other drug delivery system like transdermal drug delivery, Arya et al. (2017) worked for many years to develop a technology based on microneedle and finally designed a technique for delivery by recommending use of the microneedle patch. Arya et al. (2017) worked at Georgia Tech and Emory University who designed microneedle patch and manufactured them at Global Centre for Medical Innovation at Atlanta. Individuals between the age group of 18 to 57 were chosen as the participants for the clinical trials. Seven males and seven females were considered for each category of the test. The test was divided into several parts (Arya et al., 2017).

The effectiveness of microneedle patches: The study was conducted on four groups including the people with traditional flu shot as first group, microneedle patch (vaccine) as second group, placebo patch without drug as third group, and people who administered the patch using the instructional video as fourth group. The results obtained were quiet interesting as it was observed that the patch worked similar to the traditional flu shot. The drug bioavailability was monitored and it was same to that of first group. Hence, the patches were approved for further studies. (Arya et al., 2017).

Skin toxicity studies: The skin scoring scale was utilized in which the site at which the patches applied was evaluated on the factors, such as pain, tenderness, erythema, and swelling. Pain was evaluated on the basis of after effects, i.e., the effect after the patch is removed. Similarly, tenderness was defined on the basis of touch on the skin by the evaluator after the patch is administered and the appropriate results were obtained. (Arya et al., 2017).

For the evaluation through skin staining and microscopy, $1 \%$ gentian violet solution was used to stain the skin. After the insertion of microneedle, it was immediately removed off and the amount of stained skin was observed with the help of microscope and the punctures that microneedle made was counted, i.e., the stained part. Skin staining is calculating the microneedles that penetrated into the skin. The efficiency of microneedles was checked, i.e., microneedles that actually delivered the drug and dissolved after administration. The results obtained were satisfying as it was observed that almost $95 \%$ of the microneedles penetrated in the skin, i.e., punctured the skin layer and delivered almost $70 \%-80 \%$ of the drug after penetration (Arya et al., 2017).

Table 2. Overview of different approaches used in delivery of drug via microneedles, description and type of microneedle that follow different approach.

\begin{tabular}{llll}
\hline $\begin{array}{l}\text { Drug delivery } \\
\text { approach }\end{array}$ & Description & $\begin{array}{l}\text { Type of } \\
\text { microneedle }\end{array}$ & Reference \\
\hline Poke and patch & $\begin{array}{l}\text { Drug releases through } \\
\text { micropores generated by } \\
\text { microneedles }\end{array}$ & $\begin{array}{l}\text { Solid } \\
\text { microneedle }\end{array}$ & (Henry et al., 1998) \\
Coat and poke & $\begin{array}{l}\text { Detachment of coating } \\
\text { from the microneedle }\end{array}$ & $\begin{array}{l}\text { Drug-coated } \\
\text { microneedle }\end{array}$ & (Mcgrath et al., 2011) \\
Poke and release & $\begin{array}{l}\text { Drug diffuses and } \\
\text { dissolves through the } \\
\text { pores }\end{array}$ & $\begin{array}{l}\text { Dissolving } \\
\text { microneedle }\end{array}$ & (Chen et al., 2008) \\
Poke and flow & $\begin{array}{l}\text { Drug flows out through } \\
\text { the bore }\end{array}$ & $\begin{array}{l}\text { Hollow } \\
\text { microneedle }\end{array}$ & (Bal et al., 2010) \\
\hline
\end{tabular}

To evaluate the microneedle patches based on user surveys, participants had to answer short questions based on patches. The pain during administration, the confidence, and preference of a conventional patch or a microneedle patch were evaluated. As a result, the evaluators found that $86 \%$ were confident in applying the patch and that the majority of participants experienced no pain. In addition, it was observed that the participants preferred more microneedle patches compared to conventional injections because the patches did not cause pain and were easy to handle and use (Arya et al., 2017).

The advancement in microneedle drug delivery can be judged from the success of these microneedles in delivering drug into systemic circulation. Few of these successful systems are listed in Table 3.

\section{Applications of Microneedle Drug Delivery System}

The some of the important applications of microneedle drug delivery along with the successful product are listed in Table 4.

\section{Microneedles for vaccine delivery}

The increase in awareness among people regarding vaccination has led scientists to find new approaches for the delivery of vaccine. The recent one being microneedle drug delivery in which the antigen is directly introduced in the dermis. Thus, immune response can be achieved and vaccination therapy can be completed. This activity is carried out mostly by using dissolving type of microneedles. Various tecniques and devices like "mantoux" or "soluvia microinjection system" can be used to perform this process. According to the studies, mantoux tecique is difficult to perform as it requires professional person, whereas soluvia technique is commonly used and that too for the delivery of influenza vaccines, such as trivalent or quadrivalent or influenza type A or B (Pettis and Harvey, 2012; Van Damme et al., 2009; Vankerckhoven and Van, 2010).

Table 3. List of few microneedle drug delivery systems successful in clinical trials that can be used to deliver drug into systemic circulation.

\begin{tabular}{llll}
\hline Drug & Use & $\begin{array}{l}\text { Microneedle } \\
\text { type }\end{array}$ & Reference \\
\hline Meloxicam & Arthritis & $\begin{array}{l}\text { Dissolving } \\
\text { microneedle }\end{array}$ & (Amodwala et al., 2017) \\
Donepezil HCL & Alzheimer's disease & $\begin{array}{l}\text { Drug-coated } \\
\text { microneedle }\end{array}$ & (Kearney et al., 2016) \\
5-aminolevulinic & Skin tumors & $\begin{array}{l}\text { Coated } \\
\text { microneedle }\end{array}$ & (Donnelly et al., 2008) \\
acid & Analgesia, anti-cancer, & $\begin{array}{l}\text { Dissolving } \\
\text { microneedle }\end{array}$ & (Wu et al., 2016) \\
\hline
\end{tabular}

Table 4. List of marketed products used in specific treatment.

\begin{tabular}{lll}
\hline Product name & Purpose & Reference \\
\hline Kumetrix $^{\circledR}$ & Glucose monitoring & (Koschinsky and Heinemann, 2001) \\
Soluvia $^{\circledR}$ & Vaccine delivery & (Wiwanitkit, 2014) \\
Micronjet $^{\circledR}$ & Vaccine delivery & (Levin et al., 2014) \\
Dermaroller $^{\circledR}$ & Scars, wrinkles treatment & (Nair and Arora, 2014) \\
Nicotinell $^{\circledR}$ & $\begin{array}{l}\text { Nicotine patches for treating } \\
\text { addiction }\end{array}$ & (Moffatt et al., 2017) \\
\hline
\end{tabular}




\section{Microneedles for insulin delivery}

Many research studies were carried out for insulin delivery by various scientists, such as Martanto et al. (2004) and Henry et al. (1998), and they found that the insulin delivered through microneedle drug delivery was appropriate and it produced proper biological effect and maintained the blood glucose level. Also, bioavailability of insulin was found to be proper as insulin was introduced into the body by coating it on the microneedle which pierced the stratum corneum layer which led to the delivery of insulin. The first approach for insulin delivery was done by using 10-IU standardized insulin lispro which showed good absorption rate (Pettis and Harvey, 2012). Borosilicate glass microneedles were used (Gupta et al., 2009; 2011).

\section{Microneedles for delivery of parathyroid hormone}

It is used for the delivery of the parathyroid hormone, i.e., teriparatide. Drug-coated type of microneedles is used in it which delivers the drug after it is inserted in the skin, i.e., the drug coated gets dissolved after insertion. The delivery of parathyroid hormone through microneedle is not yet approved. But, it has undergone phase 1 and 2 studies which concluded that the drug delivered via microneedles reached three times earlier to the maximum concentration as compared to that delivered via traditional route (Pettis and Harvey, 2012). Parathyroid patches have also been prepared (Daddona et al., 2011).

\section{Microneedles for delivery of Lidocaine and other anesthetics}

The type of microneedles used here were solid and hollow microneedles. The anesthetic drug was delivered to the various participants selected for study and criteria, i.e., pain and numbness obtained were evaluated. The results showed that the pain was less as compared to that of traditional needle and numbness obtained was as effective as that of the conventional way of approaching numbness to particular part. Thus, it was concluded that microneedles were more effective than hypodermic needle in producing more numbness and less of pain which consequently worked for the betterment of patient (Pettis and Harvey, 2012). Solid-based microneedle has been formulated for delivery of lidocaine for patients to be anesthetized (Zhang et al., 2012).

\section{Microneedles for cosmetic purpose (Dermaabrasion)}

Microneedles are used for decreasing the scars, wrinkles, etc from the skin. This is achieved by puncturing the skin multiple times through microneedles, earlier which was done through hypodermic needle. The pores, thus, created through microneedles resulted in the increase of collagen growth and breaking or disruption of old collagen which caused damaged to the skin. This led to decreasing the wrinkles, also helped in treating acne. The special instrument made for this is Dermaroller ${ }^{\mathbb{B}}$. It is $12 \mathrm{~cm}$ long and consists of 192 miniature needles arranged in 24 circular arrays. The length of which is 0.5 to $3 \mathrm{~mm}$ and diameter of which is 0.1 to $0.25 \mathrm{~mm}$. These needles can be adjusted according to the depth, skin layer in which one wants the insertion (Fabbrocini et al., 2009; Nair and Arora, 2014; Pettis and Harvey, 2012).

\section{Microneedles for naltrexone}

Microneedle patches were used to treat opioiddependent patients as well as alcohol addict treatment. When patches were administered, it was found that the optimum plasma level was obtained within 2 hours after administration and the effect prolonged till 72 hours. Thus microneedles coated with naltrexone, thus delivered drug into the systemic circulation which helped block the opioid effect (Pettis and Harvey, 2012; Stinchcomb et al., 2008).

\section{Microneedles for acne scar treatment (Dermaroller)}

For acne scar treatment, microneedles are used. The area with acne scar is treated with anesthetic agent and the Dermaroller is used and allowed to move in vertical and horizontal direction. The saline pads are used for treating the bleeding which could be controlled. The process takes 20 minutes for getting completed. Also, home care derma rollers are used for delivering anti-ageing products (Dogra et al., 2014).

\section{Microneedles for glucose monitoring}

Microneedles are used indirectly for glucose monitoring. Previously, devices, namely, "Cygnus glucowatch" were used more for monitoring the glucose levels in the body (Tierney et al., 2001). Using silicon microneedles gave proper precision, appropriate needle penetration which helped extracting interstitial fluid with minimum pain which helped monitor blood glucose level. (Koschinsky and Heinemann, 2001) Commercially available glucose monitoring/sensing device is Kumetrix ${ }^{\circledR}$ which is made up of silicon microneedle (Smart and Subramanian, 2000).

\section{Microneedle patch for iron deficiency anemia}

Success in modulating microneedle patches to replace the oldest approach of using iron supplement and parenteral approaches for treating iron deficit human was achieved by using micro molding technique which helped treat anemia in patients without any gastric side effect. Rapidly dissolving type of microneedles loaded with ferric pyrophosphate which could help treat Iron deficiency anemia efficiently was formulated. On carrying out in vivo and in vitro studies, satisfying results were obtained (Maurya et al., 2018).

\section{Microneedles for transdermal protein delivery}

Microneedle mask devices have been prepared using continuous liquid interface production technique coated on polyethylene glycol base for appropriate delivery of proteins like serum albumin and ovalbumin. To avoid damage to the encapsulated protein which can eventually result in immunogenicity due to exposure to free radical polymerization procedure used to produce Continuous Liquid Interface Production-based microneedles during fabrication. The way out to this was coating microneedles after fabrication process is over. The successful delivery has been noted in studies carried out on mice for 72 hours in which sustained retention of protein was observed (Caudill et al., 2018).

\section{D printed Microneedles}

Such types are mostly used for delivery of insulin. The cone shaped polymeric microneedles have been obtained via stereo lithography technique using a biocompatible resin. To prevent rapid degradation and maintain stability of insulin, it is coated on microneedle by using inject print technique in which insulin solution is printed on each microneedle by keeping them at 
$45^{\circ} \mathrm{C}$ and repeating the process for 92 times in which 10 dots of 2 droplets are longitudinally dispensed (Pere et al., 2018).

\section{Microneedles for subcutaneous tumor}

A fast dissolving microneedle patch has been fabricated using sodium hyaluronate on to which 5 -aminolevulinic acid is coated to the tips of microneedle. This led to maximum drug utilization and avoidance of drug residue. Also, it helped overcome problems related with hydrophilicity and zwitterion nature of aminolevulinic acid. Hence, by using photodynamic therapy and sodium hyaluronate-based microneedles a dissolving microneedle of aminolevulinic acid proves to be best for treating subcutaneous tumor (Zhao et al., 2018).

\section{Patents}

The strategy of delivering drug via microneedle has resulted in several patents which are listed in Table 5. Different mechanisms for different types of microneedle were reported.

Adachi et al. (2007) developed microneedle device which helps permeate layers of skin for painless delivery of drug. Tomono (2008) utilized chitosan which is a biodegradable material for fabricating a microneedle. Lee et al. (2011) came up with an idea of developing a hermetically sealed bottom of which the microneedle array is attached at the opening of the setup of a container in which capsule kept releases drug at desired time periods.

Birchall et al. (2012) developed a system in which indicator material and therapeutic agent is coated on microneedle and the arrangements are such that drug to be delivered is delivered first and once the drug is delivered the indicator indicates the success of the drug delivered. The therapeutic agent is toward the tip and the indicator material is underneath for appropriate delivery. Herman et al. (2013) developed a system used for treating various urinary tract diseases using microneedles for drug delivery of various treatment fluids.

Levin et al. (2013) developed device that includes a syringe connected with a barrel, a plunger, and a hollow microneedle adapter. The injections, thus obtained contain microneedle adapter which are used to deliver the fluids to intradermal area. Levin, thus, devised this technique which also helps in dose sparing as it has been proven that delivering via intradermal routes produces the same efficacy as that of the doses not given in intradermal space. Vaccines are also given through this route (Levin et al., 2014).

Shaari et al. (2013) developed nasal delivery device in which in certain embodiments, the nasal delivery device comprises a substrate for administration of a composition to the nasal and/or sinus mucosa, wherein the substrate is non-absorbent

Table 5. The patents on Microneedle system.

\begin{tabular}{|c|c|c|c|c|}
\hline Sr. No & Patent Number & Title & Abstract & Reference \\
\hline 1. & US20070250018 & $\begin{array}{l}\text { Transdermal drug administration system } \\
\text { with microneedle }\end{array}$ & $\begin{array}{l}\text { Painless delivery of drug via stratum corneum to systemic circulation by } \\
\text { using microneedle device via reservoir adsorbent and drug which gets } \\
\text { dissolved in order to fulfill the purpose of drug delivery was patented } \\
\text { in } 2007 \text {. }\end{array}$ & (Adachi and Tokumoto, Higo, 2007) \\
\hline 2. & US20080200883 & Micro-needle and micro-needle patch & $\begin{array}{l}\text { Tomono suggested usage of biodegradable material for fabrication of } \\
\text { microneedle and developed a successful microneedle device. }\end{array}$ & (Tomono, 2008) \\
\hline 3. & US20110046557 & $\begin{array}{l}\text { Microneedle drug delivery system } \\
\text { including movable drug-containing } \\
\text { capsule }\end{array}$ & $\begin{array}{l}\text { Lee et al. developed movable capsules containing drug which can be } \\
\text { delivered by microneedle drug delivery system. }\end{array}$ & (Lee et al., 2011) \\
\hline 4. & US20120123341 & $\begin{array}{l}\text { Monitoring system for microneedle drug } \\
\text { delivery }\end{array}$ & $\begin{array}{l}\text { Birchal et al. (2012) developed a monitoring system in which sequential } \\
\text { coating of microneedle was possible with additional advantage of } \\
\text { indications provided directly by the device regarding the completed } \\
\text { process. }\end{array}$ & (Birchal et al., 2012) \\
\hline 5. & US20130331783 & Micro-needle bladder ballon & $\begin{array}{l}\text { Herman et al. (2013) formulated inflating ballon system using } \\
\text { microneedles which functions to puncture the inner bladder wall for } \\
\text { delivering particulates such as, stem cells, drugs, Botox for treating } \\
\text { various urinary tract disorders. }\end{array}$ & (Herman et al., 2013) \\
\hline 6. & US20130110043 & $\begin{array}{l}\text { Microneedle intradermal drug delivery } \\
\text { device with auto-disabled functionality }\end{array}$ & $\begin{array}{l}\text { Levin developed an auto disable microneedle syringes for direct } \\
\text { intradermal delivery of drugs. }\end{array}$ & (Levin, 2013) \\
\hline 7. & US20130085472 & Microneedle nasal delivery device & $\begin{array}{l}\text { The invention directed by Shaari et al. lead to nasal delivery device } \\
\text { comprising one or more microneedles, and to various methods of } \\
\text { nasally administering a composition with a nasal delivery device } \\
\text { comprising one or more microneedles. }\end{array}$ & (Shaari, 2013) \\
\hline 8. & US9017310 & $\begin{array}{l}\text { Transmucosal drug delivery device using } \\
\text { microneedles }\end{array}$ & $\begin{array}{l}\text { Uhland and Peeters } 2015 \text { prepared a device for intraluminal delivery } \\
\text { obtained by movement of microneedles inside the human skin. }\end{array}$ & (Uhland and Peeters, 2015) \\
\hline 9. & US9333330 & Multichannel microneedle & $\begin{array}{l}\text { Cannehan and Cachemaille (2016) developed a system with minimum } \\
\text { two parallel independent lumen designed to open in perpendicular } \\
\text { direction for drug delivery. }\end{array}$ & (Cannehan and Cachemaille, 2016) \\
\hline 10. & US20160144100 & Microneedle drug delivery system & $\begin{array}{l}\text { Gharib et al., } 2016 \text { developed microneedle device for fluid delivery that } \\
\text { forced drug for effective intradermal delivery or injections via needles }\end{array}$ & (Gharib et al., 2016) \\
\hline 11. & US20140005606 & $\begin{array}{l}\text { Embeddable microneedle patch for } \\
\text { transdermal drug delivery and method of } \\
\text { manufacturing the same }\end{array}$ & $\begin{array}{l}\text { Chein and Haung invented embeddable microneedle patch which } \\
\text { includes supporting substrate, shaft, biodegradable carrier and a drug } \\
\text { encapsulated in the carrier. }\end{array}$ & (Chen and Huang, 2017) \\
\hline 12. & US20170065803 & Microneedle based cell delivery & $\begin{array}{l}\text { Birchall et al. formulated microneedles for transplantation of cells } \\
\text { which tends to elevate the hair growth and helps improve the skin } \\
\text { related problems. }\end{array}$ & (Brichall et al., 2017) \\
\hline
\end{tabular}


and comprises one or more microneedles. In some embodiments, the nasal delivery device comprises a reservoir comprising one or more therapeutic agents, wherein the reservoir is in fluid communication with one or more microneedles.

Uhland and Peeters (2015) developed device for intraluminal delivery in which disrupted mucosal region helped in delivering of the drug through microneedles. The drug from the housing is dispensed in the disrupted mucosal region which is obtained via microneedles.

Cannehan and Cachemaille (2016) lead to the development of system having independent lumen connected with elongated body, head, and sharp tip with distal opening in perpendicular direction with respect to lumen used to deliver drug via stratum corneum into systemic circulation.

Gharib et al. (2016) developed system using one or more needle(s) or micro-needle arrays in which description related with shift of fluid volume from a first expansion member position to a second expansion member position drives delivery of the fluid, which can be a drug or drug solution, through the needle(s) or micro-needle arrays.

Cheng and Huang (2017) developed embeddable microneedle patch in which when the embeddable micro-needle patch for transdermal drug delivery is attached to the skin for a predetermined time, the biodegradable carrier is separated from the supporting shafts and embedded into the skin, and the biodegradable carrier swells and then degrade, so as to release the drugs, which are encapsulated in the biodegradable carrier, at a rate of $1 \% \sim 99 \%$ loaded drug per day into the skin.

Birchall and Coulman (2017) developed microneedle device for treating skin improvement or repair comprising: a plurality of microneedles attached to or integral with a supporting base member and arranged in at least one circular pattern on same wherein said microneedles are hollow and have a bore size of between 60 and $150 \mu \mathrm{m}$ diameter. Hence, subsequent growth can be observed in the field of microneedle drug delivery system.

\section{CONCLUSION}

Thus, this review article included the basics of transdermal drug delivery system as well as microneedle drug delivery system. Through this, one can understand that in the coming years, the importance of microneedle drug delivery is going to increase due to the advantages that it offers. It can replace the conventional methods of drug delivery most probably the transdermal approach. The biggest advantage that it offers is the painless treatment. Furthermore, the efficiency of increasing the penetration through the skin which is one of the biggest hurdles in transdermal drug delivery system has increased the scope of microneedle drug delivery system in the coming years. Also, there is no limitation of using only potent drugs for microneedle drug delivery system. Furthermore, patient compliance, possibility of self-administration, bioavailability, accuracy, precision, less chances of bacterial infections, and many other advantages leads to conclusion that the microneedle drug delivery system can definitely be used for betterment of people and eventually for good public health. Thus, microneedle drug delivery system obtained from the basis of transdermal drug delivery system can be used for better.

\section{AUTHORS' CONTRIBUTION}

The manuscript is conceptualized and data acquisition done by Dr. Surendra Agrawal and Ms. Suchi Gandhi; Ms. Pravina and Dr. Saraswathy critically reviewed the content and revised it.

\section{FINANCIAL SUPPORT}

None.

\section{CONFLICT OF INTERESTS}

The authors of this manuscript do not have any conflict of interest.

\section{ABBREVIATIONS}

TDDS: Transdermal drug delivery system, NDDS: Novel drug delivery system.

\section{REFERENCES}

Adachi H, Tokumoto S, Higo N, inventors. Transdermal drug administration system with microneedles. United States patent application US 11/659,894, 2007 Oct 25.

Allen L, Ansel HC. Ansel's pharmaceutical dosage forms and drug delivery systems, 10th edition, Lippincott Williams \& Wilkins, Philadelphia, USA, pp 750-1, 2014.

Amodwala S, Kumar P, Thakkar HP. Statistically optimized fast dissolving microneedle transdermal patch of meloxicam: a patient friendly approach to manage arthritis. Eur J Pharm Sci, 2017; 104:114-23.

Arya J, Henry S, Kalluri H, McAllister DV, Pewin WP, Prausnitz MR. Tolerability, usability and acceptability of dissolving microneedle patch administration in human subjects. Biomaterials, 2017; 128:1-7.

Bal S, Kruithof AC, Liebl H, Tomerius M, Bouwstra J, Lademann J, Meinke M. In vivo visualization of microneedle conduits in human skin using laser scanning microscopy. Laser Phys Lett, 2010; 7(3):242-6.

Banerjee S, Chattopadhyay P, Ghosh A, Datta P, Veer V. Aspect of adhesives in transdermal drug delivery systems. Int J Adhes Adhes, 2014; 50:70-84.

Bhowmik D, Pusupoleti KR, Duraivel S, Kumar KS. Recent approaches in transdermal drug delivery system. Pharma Innov, 2013; 2(3, Part A):99.

Bhushan B, Caspers M. An overview of additive manufacturing (3D printing) for microfabrication. Microsyst Technol, 2017; 23(4): $1117-24$.

Birchall J, Coulman S, Dev SH, Gualeni B, inventors; Cardiff University College Consultants Ltd, assignee. Microneedle based cell delivery. United States patent application US 15/122,664, 2017 Mar 9.

Birchall JC, Coulman SA, Allender CJ, Brain KR, inventors; Cardiff University College Consultants Ltd, assignee. Monitoring system for microneedle drug delivery. United States patent application US 12/809,667, 2012 May 17.

Bouwstra JA, Ponec M. The skin barrier in healthy and diseased state. Biochim Biophys Acta (BBA)-Biomembranes, 2006; 1758(12): 2080-95.

Cannehan F, Cachemaille A, inventors; Debiotech SA, assignee. Multichannel micro-needles. United States patent US 9,333,330, 2016 May 10

Caudill CL, Perry JL, Tian S, Luft JC, DeSimone JM. Spatially controlled coating of continuous liquid Interface production microneedles for transdermal protein delivery. J Control Release, 2018; 284:122-32.

Chandrasekaran S, Frazier AB. Characterization of surface micromachined metallic microneedles. J Microelectromech Syst, 2003; 12(3):289-95

Chaudhary H, Rohilla A, Rathee P, Kumar V. Optimization and formulation design of carbopol loaded Piroxicam gel using novel penetration enhancers. Int J Biol Macromol, 2013; 55:246-53. 
Cheng MC, Huang SF, inventors; National Cheng Kung University, assignee. Embeddable micro-needle patch for transdermal drug delivery and method of manufacturing the same. United States patent US 9,675,789, 2017 Jun 13.

Chetkowski RJ, Meldrum DR, Steingold KA, Randle D, Lu JK, Eggena P, Hershman JM, Alkjaersig NK, Fletcher AP, Judd HL. Biologic effects of transdermal estradiol. N Engl J Med, 1986; 314(25):1615-20.

Chu LY, Choi SO, Prausnitz MR. Fabrication of dissolving polymer microneedles for controlled drug encapsulation and delivery: bubble and pedestal microneedle designs. J Pharma Sci, 2010; 99(10): 4228-38.

Clissold SP, Heel RC. Transdermal hyoscine (scopolamine). Drugs, 1985; 29(3):189-207.

Cormier M, Johnson B, Ameri M, Nyam K, Libiran L, Zhang DD, Daddona P. Transdermal delivery of desmopressin using a coated microneedle array patch system. J Control Release, 2004; 97(3): $503-11$.

Daddona PE, Matriano JA, Mandema J, Maa YF. Parathyroid hormone (1-34)-coated microneedle patch system: clinical pharmacokinetics and pharmacodynamics for treatment of osteoporosis. Pharma Res, 2011; 28(1):159-65.

Dogra S, Yadav S, Sarangal R. Microneedling for acne scars in A sian skin type: an effective low cost treatment modality. J Cosmetic Dermatol, 2014; 13(3):180-7.

Donnelly RF, Singh TR, Woolfson AD. Microneedle-based drug delivery systems: microfabrication, drug delivery, and safety. Drug Delivery, 2010; 17(4):187-207.

Duarah S, Sharma M, Wen J. Recent advances in microneedlebased drug delivery: Special emphasis on its use in paediatric population. Eur J Pharm Biopharm, 2019; 136:48-69.

Fabbrocini G, Fardella N, Monfrecola A, Proietti I, Innocenzi D. Acne scarring treatment using skin needling. Clin Exp Dermatol Exp Dermatol, 2009; 34(8):874-9.

Fofonoff T, Wiseman C, Dyer R, Malasek J, Burgert J, Martel S, Hunter I, Hatsopoulos N, Donoghue J. Mechanical assembly of a microelectrode array for use in a wireless intracortical recording device. In Microtechnologies in Medicine \& Biology 2nd Annual International IEEEEMB Special Topic Conference, IEEE, pp 269-272, 2002.

Gardeniers HJ, Luttge R, Berenschot EJ, De Boer MJ, Yeshurun SY, Hefetz M, van't Oever R, van den Berg A. Silicon micromachined hollow microneedles for transdermal liquid transport. J Microelectromech Syst, 2003; 12(6):855-62.

Gharib M, Cosse J, Rider S, Wang C, inventors; California Institute of Technology, assignee. Micro-needle drug delivery systems. United States patent application US 14/947,767, 2016 May 26.

Gill HS, Prausnitz MR. Coated microneedles for transdermal delivery. J Control Release, 2007a; 117(2):227-37.

Gill HS, Prausnitz MR. Coating formulations for microneedles. Pharma Res, 2007b; 24(7):1369-80.

Guo C, Zhou L, Lv J. Effects of expandable graphite and modified ammonium polyphosphate on the flame-retardant and mechanical properties of wood flour-polypropylene composites. Polym Polym Compos, 2013; 21(7):449-56.

Gupta J, Felner EI, Prausnitz MR. Minimally invasive insulin delivery in subjects with type 1 diabetes using hollow microneedles. Diabetes Technol Ther, 2009; 11(6):329-37.

Gupta J, Felner EI, Prausnitz MR. Rapid pharmacokinetics of intradermal insulin administered using microneedles in type 1 diabetes subjects. Diabetes Technol Ther, 2011; 13(4):451-6.

Henry S, McAllister DV, Allen MG, Prausnitz MR. Microfabricated microneedles: a novel approach to transdermal drug delivery. J Pharma Sci, 1998; 87(8):922-5.

Herman CL, Borgos NA, Cierzan KL, inventors; AMS Research LLC, assignee. Micro-needle bladder balloon. United States patent application US 13/993,752, 2013 Dec 12.
Johnson AC, Wise KD. A robust batch-fabricated high-density cochlear electrode array. InMicro Electro Mechanical Systems (MEMS), 2010 IEEE 23rd International Conference, 2010 Jan 24, IEEE, pp 1007-10.

Kaur M, Ita KB, Popova IE, Parikh SJ, Bair DA. Microneedleassisted delivery of verapamil hydrochloride and amlodipine besylate. Eur J Pharma Biopharma, 2014; 86(2):284-91.

Kaushik S, Hord AH, Denson DD, McAllister DV, Smitra S, Allen MG, Prausnitz MR. Lack of pain associated with microfabricated microneedles. Anesth Analg, 2001; 92(2):502-4.

Kearney MC, Caffarel-Salvador E, Fallows SJ, McCarthy HO, Donnelly RF. Microneedle-mediated delivery of donepezil: potential for improved treatment options in Alzheimer's disease. Eur J Pharma Biopharma, 2016; 103:43-50.

Kesarwani A, Yadav AK, Singh S, Gautam H, Singh HN, Sharma A, Yadav C. Theoretical aspects of transdermal drug delivery system. Bull Pharm Res, 2013; 3(2):78-89.

Kim JG, Sohn SK, Kim DH, Baek JH, Chae YS, Bae NY, Kim SY, Lee KB. Effectiveness of transdermal fentanyl patch for treatment of acute pain due to oral mucositis in patients receiving stem cell transplantation. In Transplantation proceedings (Vol. 37, No. 10, pp 4488-4491), 2005 Dec 1, Elsevier.

Kong XQ, Zhou $\mathrm{P}$, Wu CW. Numerical simulation of microneedles' insertion into skin. Computer methods in biomechanics and biomedical engineering, 2011; 14(9):827-35.

Koschinsky T, Heinemann L. Sensors for glucose monitoring: technical and clinical aspects. Diabetes/Metab Res Rev, 2001; 17(2): $113-23$.

Kotzar G, Freas M, Abel P, Fleischman A, Roy S, Zorman C, Moran JM, Melzak J. Evaluation of MEMS materials of construction for implantable medical devices. Biomaterials, 2002; 23(13):2737-50.

Koutsonanos DG, del Pilar Martin M, Zarnitsyn VG, Sullivan SP, Compans RW, Prausnitz MR, Skountzou I. Transdermal influenza immunization with vaccine-coated microneedle arrays. PLoS One, 2009; 4(3):e4773.

Kshirsagar NA. Drug delivery systems. Indian J Pharmacol, 2000; 32(4):S54-61.

Kurz A, Farlow M, Lefevre G. Pharmacokinetics of a nove transdermal rivastigmine patch for the treatment of Alzheimer's disease: a review. Int J Clin Pract, 2009; 63(5):799-805.

Lampe MA, Burlingame AL, Whitney J, Williams ML, Brown BE, Roitman E, Elias PM. Human stratum corneum lipids: characterization and regional variations. J Lipid Res, 1983; 24(2):120-30.

Larraneta E, Lutton RE, Woolfson AD, Donnelly RF. Microneedle arrays as transdermal and intradermal drug delivery systems: materials science, manufacture and commercial development. Mater Sci Eng R: Rep, 2016; 104:1-32.

Laurent A, Mistretta F, Bottigioli D, Dahel K, Goujon C, Nicolas JF, Hennino A, Laurent PE. Echographic measurement of skin thickness in adults by high frequency ultrasound to assess the appropriate microneedle length for intradermal delivery of vaccines. Vaccine, 2007; 25(34): 6423-30.

Ledger PW. Skin biological issues in electrically enhanced transdermal delivery. Adv Drug Deliv Rev, 1992; 9(2-3):289-307.

Lee JW, Choi SO, Felner EI, Prausnitz MR. Dissolving microneedle patch for transdermal delivery of human growth hormone. Small, 2011; 7(4):531-9.

Lee JW, Park JH, Prausnitz MR. Dissolving microneedles for transdermal drug delivery. Biomaterials, 2008; 29(13):2113-24.

Lee SS, Sul BJ, Han MH, inventors; MITI SYSTEMS Inc, assignee. Microneedle drug delivery system including movable drugcontaining capsule. United States patent application US 12/894,924, 2011 Feb 24.

Levin Y, inventor; NanoPass Tech Ltd, assignee. Microneedle Intradermal Drug Delivery Device with Auto-Disable Functionality. United States patent application US 13/661,059, 2013 May 2. 
Levin Y, Kochba E, Kenney R. Clinical evaluation of a novel microneedle device for intradermal delivery of an influenza vaccine: are all delivery methods the same? Vaccine, 2014; 32(34):4249-52.

Li CG, Lee CY, Lee K, Jung H. An optimized hollow microneedle for minimally invasive blood extraction. Biomed Microdevices, 2013; 15(1):17-25.

Martanto W, Davis SP, Holiday NR, Wang J, Gill HS, Prausnitz MR. Transdermal delivery of insulin using microneedles in vivo. Pharma Res, 2004; 21(6):947-52.

Matriano JA, Cormier M, Johnson J, Young WA, Buttery M, Nyam K, Daddona PE. Macroflux ${ }^{\circledR}$ microprojection array patch technology: a new and efficient approach for intracutaneous immunization. Pharma Res, 2002; 19(1):63-70.

Matteucci M, Fanetti MA, Casella M, Gramatica F, Gavioli L, Tormen M, Grenci G, De Angelis F, Di Fabrizio EN. Poly vinyl alcohol re-usable masters for microneedle replication. Microelectron Eng, 2009; 86(4-6):752-6.

Maurya A, Nanjappa SH, Honnavar S, Salwa M, Murthy SN. Rapidly dissolving microneedle patches for transdermal iron replenishment therapy. J Pharm Sci, 2018; 107(6):1642-7.

McGrath MG, Vrdoljak A, O’Mahony C, Oliveira JC, Moore AC, Crean AM. Determination of parameters for successful spray coating of silicon microneedle arrays. Int J Pharm, 2011; 415(1-2):140-9.

Miyano T, Tobinaga Y, Kanno T, Matsuzaki Y, Takeda H, Wakui M, Hanada K. Sugar micro needles as transdermic drug delivery system. Biomed Microdevices, 2005; 7(3):185-8.

Moffatt K, Wang Y, Singh TR, Donnelly RF. Microneedles for enhanced transdermal and intraocular drug delivery. Curr Opin Pharmacol, 2017; 36:14-21.

Moga KA, Bickford LR, Geil RD, Dunn SS, Pandya AA, Wang Y, Fain JH, Archuleta CF, O'Neill AT, DeSimone JM. Rapidly-dissolvable microneedle patches via a highly scalable and reproducible soft lithography approach. Adv Mater, 2013; 25(36):5060-6.

Nair PA, Arora TH. Microneedling using dermaroller: A means of collagen induction therapy. Gujarat Med J, 2014; 69(1):24-7.

Park JH, Allen MG, Prausnitz MR. Biodegradable polymer microneedles: fabrication, mechanics and transdermal drug delivery. J Control Release, 2005; 104(1):51-66.

Park JH, Allen MG, Prausnitz MR. Polymer microneedles for controlled-release drug delivery. Pharma Res, 2006; 23(5):1008-19.

Patel D, Chaudhary SA, Parmar B, Bhura N. Transdermal drug delivery system: a review. Pharma Innov, 2012; 1(4):66-75.

Pere CP, Economidou SN, Lall G, Ziraud C, Boateng JS, Alexander BD, Lamprou DA, Douroumis D. 3D printed microneedles for insulin skin delivery. Int J Pharm, 2018; 544(2):425-32.

Pettis RJ, Harvey AJ. Microneedle delivery: clinical studies and emerging medical applications. Ther Deliv, 2012; 3(3):357-71.

Quinn HL, Kearney MC, Courtenay AJ, McCrudden MT, Donnelly RF. The role of microneedles for drug and vaccine delivery. Expert Opin Drug Deliv, 2014; 11(11):1769-80.

Rayment CM, Kaul AF, Garfield JM. Comparative acceptance of three transdermal nitroglycerin placebo patches. Am J Hosp Pharm, 1985 42:1362-5.

Raza R, Mittal A, Kumar P, Alam S, Prakash S, Chauhan N. Approaches and evaluation of transdermal drug delivery system. Int J Drug Dev Res, 2015; 7(1):222-33.

Roxhed N, Griss P. Membrane-sealed hollow microneedles and related administration schemes for transdermal drug delivery. Biomed Microdevices, 2008; 10(2):271-9.

Roxhed N, Samel B, Nordquist L, Griss P, Stemme G. Painless drug delivery through microneedle-based transdermal patches featuring active infusion. IEEE Transact Biomed Eng, 2008; 55(3):1063-71.

Sammoura F, Kang J, Heo YM, Jung T, Lin L. Polymeric microneedle fabrication using a microinjection molding technique. Microsyst Technol, 2007; 13(5-6):517-22.
Seo JM, Kim SJ, Chung H, Kim ET, Yu HG, Yu YS. Biocompatibility of polyimide microelectrode array for retinal stimulation. Mater Sci Eng C, 2004; 24(1-2):185-9.

Shaari C, inventor; Toxcure LLC, assignee. Microneedle nasal delivery device. United States patent application US 13/583,446, 2013 Apr 4.

Silpi C, Manish B, Kumar TR. Microneedles in transdermal drug delivery: an unique painless option. Int Res J Pharm, 2011; 2(4):72-8.

Smart WH, Subramanian K. The use of silicon microfabrication technology in painless blood glucose monitoring. Diabetes Technol Ther, 2000; 2(4):549-59.

Stinchcomb A, Banks S, Pinninti R, inventors; University of Kentucky Research Foundation, assignee. Transdermal delivery of naltrexone hydrochloride, naltrexol hydrochloride, and bis (hydroxymethyl) propionyl-3-0 ester naltrexone using microneedles. United States patent application US 11/812,249, 2008 Jan 10

Sullivan SP, Murthy N, Prausnitz MR. Minimally invasive protein delivery with rapidly dissolving polymer microneedles. Adv Mater, 2008; 20(5):933-8.

Tierney MJ, Tamada JA, Potts RO, Jovanovic L, Garg S, Cygnus Research Team. Clinical evaluation of the GlucoWatch ${ }^{\circledR}$ biographer: a continual, non-invasive glucose monitor for patients with diabetes. Biosens Bioelectron, 2001; 16(9-12):621-9.

Tomono T, inventor; Toppan Printing Co Ltd, assignee. Microneedle and micro-needle patch. United States patent application US 12/081,592, 2008 Aug 21

Torin Huzil J, Sivaloganathan S, Kohandel M, Foldvari M. Drug delivery through the skin: molecular simulations of barrier lipids to design more effective noninvasive dermal and transdermal delivery systems for small molecules, biologics, and cosmetics. Wiley Interdiscip Rev Nanomed Nanobiotechnol, 2011; 3(5):449-62.

Uhland S, Peeters E, inventors; Palo Alto Research Center Inc, assignee. Transmucosal drug delivery device and method including microneedles. United States patent US 9,017,310, 2015 Apr 28.

Utian WH. Transdermal estradiol overall safety profile. Am J Obstet Gynecol, 1987; 156(5):1335-8.

Van Damme P, Oosterhuis-Kafeja F, Van der Wielen M, Almagor Y, Sharon O, Levin Y. Safety and efficacy of a novel microneedle device for dose sparing intradermal influenza vaccination in healthy adults. Vaccine, $2009 ; 27(3): 454-9$.

Van der Maaden K, Jiskoot W, Bouwstra J. Microneedle technologies for (trans) dermal drug and vaccine delivery. J Contro Release, 2012; 161(2):645-55.

Vankerckhoven V, Van Damme P. Clinical studies assessing immunogenicity and safety of intradermally administered influenza vaccines. Expert Opin Drug Deliv, 2010; 7(9):1109-25.

Vicente-Perez EM, Larrañeta E, McCrudden MT, Kissenpfennig A, Hegarty S, McCarthy HO, Donnelly RF. Repeat application of microneedles does not alter skin appearance or barrier function and causes no measurable disturbance of serum biomarkers of infection, inflammation or immunity in mice in vivo. Eur J Pharm Biopharm, 2017; 117: $400-7$

Wang C, Swerdloff RS, Iranmanesh A, Dobs A, Snyder PJ, Cunningham G, Matsumoto AM, Weber T, Berman the testosterone gel study group N. Transdermal testosterone gel improves sexual function, mood, muscle strength, and body composition parameters in hypogonadal men. J Clin Endocrinol Metab, 2000; 85(8):2839-53.

Wang PM, Cornwell M, Hill J, Prausnitz MR. Precise microinjection into skin using hollow microneedles. J Invest Dermatol, $2006 ; 126(5): 1080-7$

Wang R, Zhao W, Wang W, Li Z. A flexible microneedle electrode array with solid silicon needles. J Microelectromech Syst, 2012; 21(5):1084-9.

Wang T, Yang W, Huang H, Fu C. A novel fabrication method of flexible micro electrode array for neural recording. InMicro Electro 
Mechanical Systems, 2007. MEMS. IEEE 20th International Conference, 2007 Jan 21, IEEE, pp 295-300.

Wang $\mathrm{M}, \mathrm{Hu} \mathrm{L}, \mathrm{Xu} \mathrm{C}$. Recent advances in the design of polymeric microneedles for transdermal drug delivery and biosensing. Lab Chip, 2017; 17(8):1373-87.

Wei-Ze L, Mei-Rong H, Jian-Ping Z, Yong-Qiang Z, Bao-Hua $\mathrm{H}$, Ting L, Yong Z. Super-short solid silicon microneedles for transdermal drug delivery applications. Int J Pharm, 2010; 389(1-2):122-9.

Wiedersberg S, Guy RH. Transdermal drug delivery: $30+$ years of war and still fighting! J Control Release, 2014; 190:150-6.

Wiwanitkit V. Intradermal trivalent influenza vaccination in nursing home older adults. J Am Med Dir Assoc, 2014; 15(10):773.

Wokovich AM, Prodduturi S, Doub WH, Hussain AS, Buhse LF. Transdermal drug delivery system (TDDS) adhesion as a critical safety, efficacy and quality attribute. Eur J Pharm Biopharm, 2006; 64(1):1-8.

Wu X, Chen Y, Gui S, Wu X, Chen L, Cao Y, Yin D, Ma P. Sinomenine hydrochloride-loaded dissolving microneedles enhanced its absorption in rabbits. Pharm Dev Technol, 2016; 21(7):787-93.

Wu Y, Qiu Y, Zhang S, Qin G, Gao Y. Microneedle-based drug delivery: studies on delivery parameters and biocompatibility. Biomed Microdevices, 2008; 10(5):601-10.
Yue R, Wang Y, Liu L, inventors; Tsinghua University, assignee. $3 \mathrm{~d}$ solid or hollow silicon microneedle and microknife with"-" shape structure. United States patent application US 12/296,672, 2009 Apr 9.

Zhang Y, Brown K, Siebenaler K, Determan A, Dohmeier D, Hansen K. Development of lidocaine-coated microneedle product for rapid, safe, and prolonged local analgesic action. Pharm Res, 2012; 29(1): $170-7$.

Zhao X, Li X, Zhang P, Du J, Wang Y. Tip-loaded fast-dissolving microneedle patches for photodynamic therapy of subcutaneous tumor. J Control Release, 2018; 286:201-9.

How to cite this article:

Agrawal S, Gandhi SN, Gurjar P, Saraswathy N. Microneedles: An advancement to transdermal drug delivery system approach. J Appl Pharm Sci, 2020; 10(03):149-159. 